\title{
A Case of Benign Lymphoid Hyperplasia of Buccal Mucosa
}

\author{
Toshihide Watanabe*, Chonji Fukumoto, Kazuya Hiroshima, Kohei Kawasaki
}

Department of Dental and Oral Surgery, Kimitsu Chuo Hospital, Japan

Copyright@2017 by authors, all rights reserved. Authors agree that this article remains permanently open access under the terms of the Creative Commons Attribution License 4.0 International License

\begin{abstract}
Benign lymphoid hyperplasia (BLH) is a rare type of lymphoproliferative disease of the oral mucosa. The present study reports a 61-year-old man who presented to the hospital with a soft polyp formation in the left buccal mucosa. He was suspected with a granuloma from cracked tooth, and an excisional biopsy was performed under local anesthesia. The histopathological examination of the specimen confirmed BLH. The patient's condition was well and free of disease at 2 years after the surgery. In this present case study, we concluded that BLH may be considered as a differential diagnosis of lymphoid disease in the oral soft tissue.
\end{abstract}

Keywords Benign Lymphoid Hyperplasia (BLH), Reactive Lymphoid Hyperplasia (RLH), Pseudolymphoma, Follicular Lymphoid Hyperplasia, Lymphoid Tissue, Lymphoproliferative Disorders, Mouth Mucosa

\section{Introduction}

Swelling of soft tissue underlying the oral mucosa is frequently observed. The clinical manifestation includes the occurrence of fibroma, mucocele, and abscess. Recognizing these symptoms with the lymphoproliferative disease is difficult at initial stages of diagnosis. Lymphoma is considered to be the most common type of lymphoproliferative disease. Benign lymphoid hyperplasia (BLH), which is also known as reactive lymphoid hyperplasia, pseudolymphoma and follicular lymphoid hyperplasia, is a rare type of lymphoproliferative disease of the oral mucosa. The histological features of the lymphatic-tissue reveal its response to a variety of stimulations [1-8].

For effective clinical interventions, it is important to distinguish between BLH, follicular lymphoma, and mucosa-associated lymphoid tissue (MALT) lymphoma. A review of the reports on BLH revealed the importance of clinic pathological findings in differentiating between these malignant lymphomas $[3,7]$.
In oral mucosa, hard palate is the most commonly affected site in the disease. In this report, a case of BLH of buccal mucosa has been reported. We have also reviewed the clinic pathological features of BLH and made comparisons with the disease.

\section{Case Presentation}

A 61-year-old man was referred to the Division of Dental and Oral Surgery, Kimitsu Chuo Hospital, with complaints of a soft polyp formation in the left buccal mucosa. At the beginning, he thought of this lesion as vesicle cause of a burn. But there was no change in the symptom for 1 month, and he remained anxious about this polyp. On examination, a painless/soft swelling of $11 \times 8 \mathrm{~mm}$ in diameter with well-demarcated margins and an intact mucosa (Figure 1) was observed.

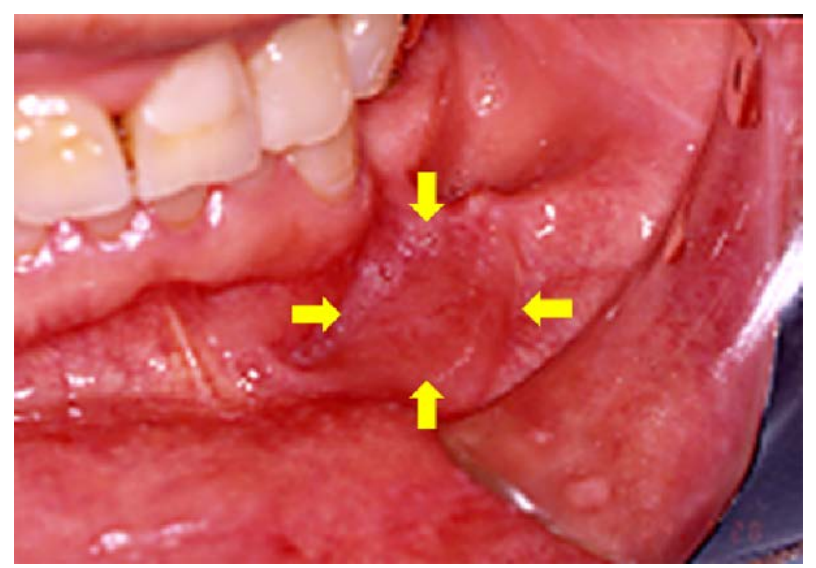

Figure 1. Intraoral preoperative view of lesion. Nodular lesion (arrows) in the left buccal mucosa

The color of this lesion was similar to that of other lesions in the oral mucosa. In the first premolar of left mandibular, although the spontaneous and occlusal pain was negative, percussion pain was positive. Dental radiograph showed that the root of this tooth was cracked (Figure 2). The patient did not have any past medical or family history of the disease. 
General examination, along with biochemical and hematological parameters, was found to be within the normal limits. We extracted the cracked tooth and diagnosed this polyp as granuloma because of the cracked root of the first premolar teeth of the mandible. However, the polyp revealed no significant change. Thus, excisional biopsy of the polyp was further performed (Figure 3).

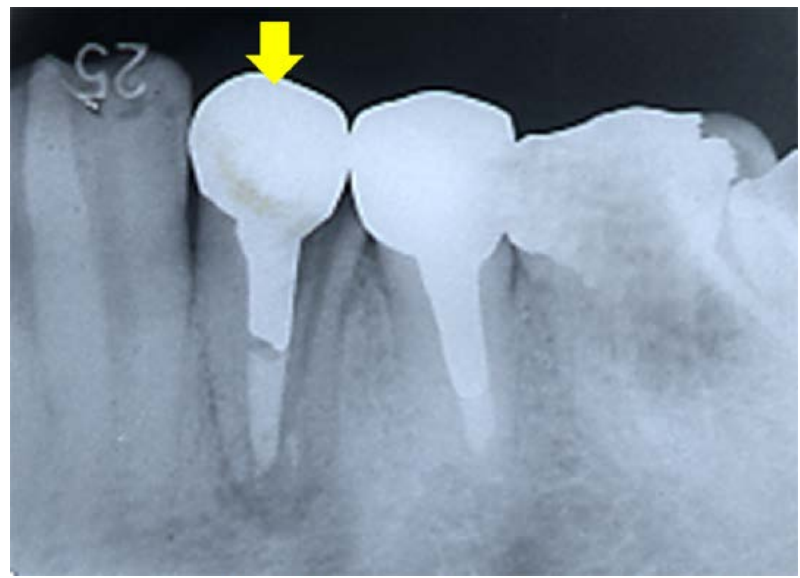

Figure 2. Dental radiograph. The first premolar of left mandibular (arrows) showed a cracked root

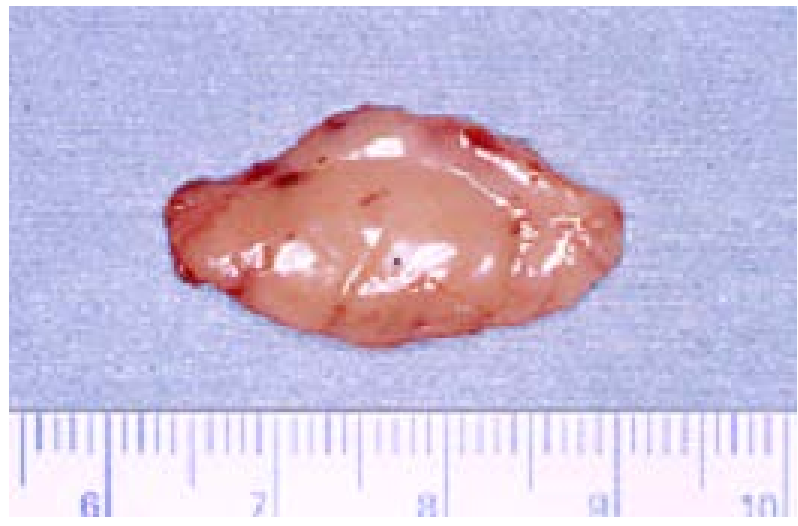

Figure 3. Surgical specimen

Histological examination of the specimen for structures of germinal centers, which were stained with hematoxylin-eosin, was preserved. It showed the presence of prominent germinal centers of centroblast-centrocyte cycling and many tingled-body macrophages, surrounded by a dense population of small regular lymphocytes (Figure 4). The immunohistochemical study was also performed according to the avidin-biotin-complex method. The immunohistochemical staining showed that LCA, L-26, CD79 $\alpha$, and UCHL-1 were positive, and CD10 and CD56 were negative. Bcl-2 and CD23 were positive in the mantle zone, and follicle center was negative (Table 1). On the basis of these features, the final diagnosis was confirmed as benign lymphoid hyperplasia of the buccal mucosa. No further treatment was given. On follow-up after 2 years, there were no abnormal findings in the buccal mucosa.
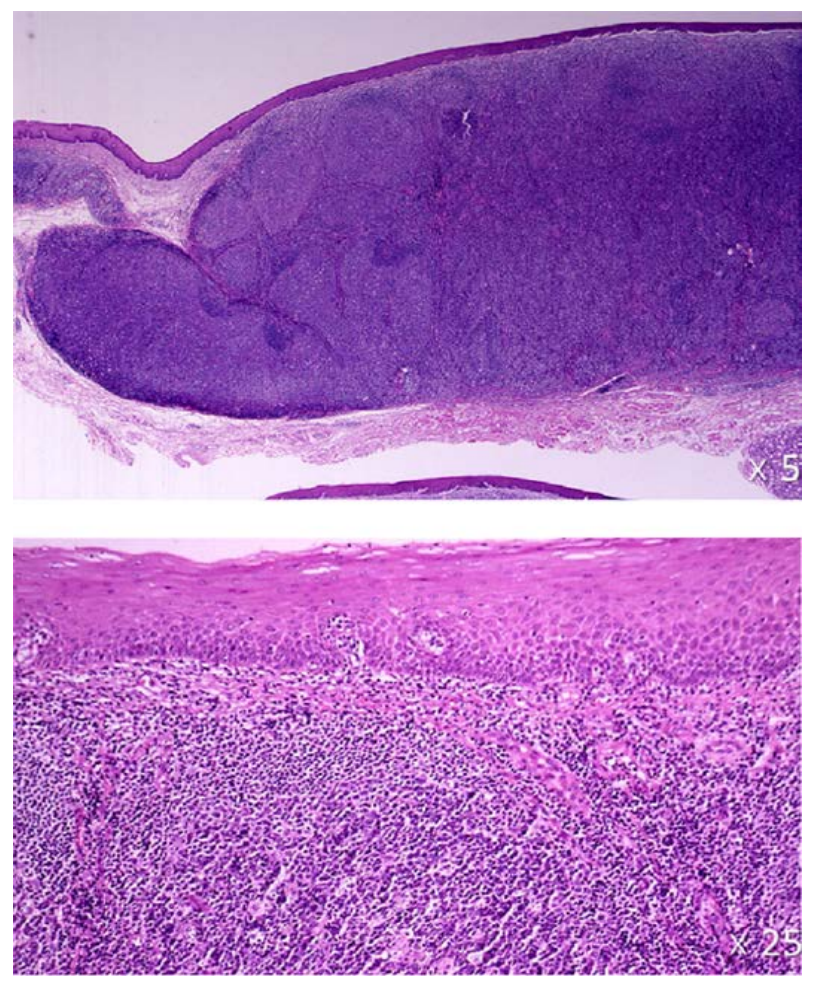

Figure 4. Histopathologic section (hematoxylin and eosin stain)

Table 1. Results of immunohistochemical staining

\begin{tabular}{|c|c|c|}
\hline Antibody & Specificity & Result \\
\hline L-26 & B-cells & Positive \\
\hline CD79 a & $\begin{array}{c}\text { B-cell lymphomas, leukemias of } \\
\text { precursor B-cell type, and some } \\
\text { myelomas }\end{array}$ & Positive \\
\hline UCHL-1 & T-cells & Positive \\
\hline CD-56 & NK-cells, some T-cells & Negative \\
\hline CD-10 & Some B-cells & Negative \\
\hline CD-23 & $\begin{array}{c}\text { Some B-cells, monocyte, follicular } \\
\text { dendritic cells }\end{array}$ & $\begin{array}{c}\text { Follicle: } \\
\text { Positive }\end{array}$ \\
\hline bcl-2 & $\begin{array}{c}\text { Cells of follicular lymphoma and } \\
\text { various diffused lymphoproliferative } \\
\text { diseases }\end{array}$ & $\begin{array}{c}\text { Follicle: } \\
\text { Positive }\end{array}$ \\
\hline
\end{tabular}

\section{Discussion}

In this case, the clinical diagnosis was granuloma according to the cracked root of the first premolar tooth of the mandible. However, the final diagnosis was BLH in the buccal mucosa, based on the histological features. Many cases of the lymphoproliferative disease have been reported in the gastrointestinal tract, lung, skin, and nose $[3,6]$. In the oral mucosa, the occurrence of lymphoproliferative disease is rare. If it occurs, it mainly affects the hard palate. In almost all cases, the primary treatment of BLH is surgical excision. In our case, we performed local excision, and the postoperative course was uneventful.

The term, reactive lymphoid hyperplasia (RLH), was first used by Smith et al. in 1958 [9]. The first report on oral 
mucosa was made by Adkins in 1973, and the symptom was called lymphoid hyperplasia [5, 9]. Subsequent reports were accomplished by the names lymphoid hyperplasia, pseudolymphoma, reactive lymphoid hyperplasia, and so on.

MALT lymphoma was proposed by Isaacson in 1983 that became a clinic pathological entity. Histopathological examination reveals the presence of lymph epithelial lesion (LEL), centrocyte-like cells (the CCL cell), a blood plasmacytic cell differentiation and colonization, and so on, confirming the presence of MALT [10].

After MALT lymphoma, the cases that reported RLH were included in the group. The case with inflammatory change was called benign RLH. Takano et al. classified RLH into two types, benign lymphoid hyperplasia (BLH) and atypical lymphoid hyperplasia (ALH) at gastric lymphoproliferative disease [11]. The histological features of BLH were a lymphoproliferative disease with hyper formation of lymphoid follicles. Reactive germinal centers, which vary in size and shape with prominent tingible body macrophages and a polymorphic lymphoid cell population, sharply defined the mantle zones and interfollicular areas populated by small lymphocytes, plasma cells and immunoblasts $[14,15]$. Compared with BLH, ALH has the following characteristics. The germinal-center of the follicle and the boundary of mantle zone are indistinct. The appearance of the atypia lymphocyte is sometimes seen. It points out the possibility of the switchover to MALT lymphoma.

The past literature showed the development of such a lymphotropic disease from the chronic inflammation, which was accompanied by the auto-aggressive mechanism [16]. In the extranodal lymphoma, the relation between Epstein-Barr virus (EBV), Human Immunodeficiency virus (HIV), and certain other entities has been suggested. Sjogren syndrome, Castleman disease, and various infection diseases have also been pointed out $[4,13]$.

There are reports pointing at the chronic continuous stimulation in the mouth from the removable prosthesis in the palate [16, 17]. The use of tobacco, alcohol, and medication was found to be associated with worsening the disease symptoms [3]. However, these stimulations have not been documented in most of the reported cases. In the example, the root of the cracked tooth existed. However, the influence of the continuous stimulation from this part was unclear and negative because it had no direct contact to BLH.

When diagnosing $\mathrm{BLH}$, the distinction of follicular lymphoma and the MALT lymphoma is important. But there is no absolute view about the diagnosis. The diagnosis must be carried out by the relative comparison of the pathological findings. In the case of BLH, which is placed as the reactive lymphoproliferative disease, MALT lymphoma is a lymphoproliferative disease with a penumbra and an uncertain neoplasm character. In the MALT lymphoma, CCL cell is attended by the part in mantle zone and LEL is formed, whereas there is a tendency of a clearer mantle zone in BLH [10].

In BLH and MALT lymphomas, the cell compositions are varied, and the follicle size is irregular. As for the follicular lymphoma, which is a pathological change in neoplasm, the composition of cell, the follicle structure, and the size were comparatively regular, circular and uniform (Table 2) [14, 15, 18].

Although the BLH and MALT lymphomas witness higher mitosis rates, these have a characteristic of the non-neoplastic-disease, hence, fitting into the follicular lymphoma group. The existence of tingibled-body macrophage is a useful finding in the diagnosis of BLH.

Based on immunohistological studies, differences are observed between the three diseases regarding the expression of CD10, bcl-2 (Table 2). The immunostained ALH cells show high expression of CD10, bcl-2. The possibility of transformation of the above ALH into follicular lymphoma also becomes high, and its switching over from ALH to the MALT lymphoma type cannot be denied [13].

Although the present case was diagnosed with BLH and pathological malignancy was not observed, a periodic follow-up is needed.

Table 2. Pathological comparison of BLH, ALH and follicular lymphoma

\begin{tabular}{|c|c|c|c|c|c|c|c|}
\hline & $\begin{array}{c}\text { Size of } \\
\text { the follicle } \\
\text { structure }\end{array}$ & $\begin{array}{c}\text { Form of } \\
\text { the follicle }\end{array}$ & $\begin{array}{c}\text { Boundary } \\
\text { of } \\
\text { the follicle }\end{array}$ & $\begin{array}{c}\text { Cell } \\
\text { composition }\end{array}$ & Mitosis & \multicolumn{2}{|c|}{$\begin{array}{c}\text { Immunohistochemical } \\
\text { staining }\end{array}$} \\
\cline { 4 - 7 } & Irregular & Irregular & Clear & Uniformity & Rare & -10 & Bcl-2 \\
\hline $\begin{array}{c}\text { Benign lymphoid } \\
\text { hyperplasia } \\
\text { lymphical } \\
\text { hyperplasia }\end{array}$ & Irregular & Irregular & $\begin{array}{c}\text { Clear } \sim \text { not } \\
\text { clear }\end{array}$ & Various & Multitude & $+/-$ & $+/-$ \\
\hline $\begin{array}{c}\text { Follicular } \\
\text { Lymphoma }\end{array}$ & Regular & Irregular & Not clear & $\begin{array}{c}\text { CCL } \\
\text { main constituent } \\
\text { and various }\end{array}$ & Multitude & + \\
\hline
\end{tabular}




\section{Conclusions}

We reported a BLH of buccal mucosa in a 61-year-old male patient and also concluded immunohistochemical tests for confirming the final diagnosis of BLH. Though regarded as rare, BLH may be considered as a differential diagnosis of lymphoid disease in the oral soft tissue.

\section{Conflict of Interest}

The authors declare that there is no conflict of interests regarding the publication of this paper.

\section{Acknowledgements}

We would like to express the deepest appreciation to Dr. Osamu Matsuzaki for his pathological diagnosis and valuable support.

\section{REFERENCES}

[1] S.S. Napier, C. Newlands. Benign lymphoid hyperplasia of the palate: report of two cases and immunohistochemical profile, Journal of Oral Pathology \& Medicine, Vol.19, No.5, 221-225, 1990.

[2] P.J. Kurtin. How do You Distinguish Benign from Malignant Extranodal Small B-Cell Proliferations? American Journal of Clinical Pathology, Vol.111, No.1Suppl1, S119-125, 1999.

[3] G. Bradley, J.H.P. Main, B.D. Birt, L. From. Benign Lymphoid Hyperplasia of the Palate, Journal of Oral Pathology, Vol.16, No.1, 18-26, 1987.

[4] A. Kolokotronis, I. Dimitrakopoulos, A. Asimaki. Follicular lymphoid hyperplalsia of the palate: Report of a case and review of the literature, Oral Surgery, Oral Medicine, Oral Pathology, Oral Radiology, Vol.96, No.2, 172-175, 2003.

[5] S. Carnelio, G. Rodrigues. Benign lymphoid hyperplasia of the tongue masquerading as carcinoma: case report and literature review, Journal of Contemporary Dental Practice, Vol.6, No.3, 111-119, 2005.

[6] M.K. McElroy, A.A. Kulidjian, R. Sumit, N. Weidner. Benign lymphoid hyperplasia (pseudolymphoma) of soft tissue, Human Pathology, Vol.42, No.11, 1813-1818, 2011.

[7] J.K. Manveen, R. Subramanyam, G. Harshaminder, S. Madhu, R. Narula. Primary B-cell MALT lymphoma of the palate: A case report and distinction from benign lymphoid hyperplasia (pseudolymphoma), Journal of Oral and Maxillofacial Pathology, Vol.16, No.1, 97-102, 2012.

[8] M.A. Gordón-Núñez, O.D.R. Méndes Jr, L.M.M. Silva, H.C. Galvão. Follicular Lymphoid Hyperplasia in Palate: A Case Report with Immunohistochemical Analysis and Review, Journal of Clinical Case Reports, Vol.2, No.9, 2012.

[9] J.L.Jr. Smith, E.B. Helwig. Malignant lymphoma of the stomach; its diagnosis, distinction and biologic behavior, American Journal of Pathology, Vol.34, 553, 1958.

[10] P. Isaacson, D.H. Wright. Malignant lymphoma of mucosa associated lymphoid tissue; A distinctive type of B-cell lymphoma, Cancer, Vol.52, No.8, 1410-1416, 1983.

[11] Y. Takano, Y. Kato, H. Sugano. Histopathological and immunohistochemical study of atypical lymphoid hyperplasia and benign lymphoid hyperplasia of the stomach, Japanese Journal of Cancer Research, Vol. 83, No.3, 288-293, 1992.

[12] K.F. Adkins. Lymphoid Hyperplasia of the Oral Mucosa, Australian Dental Journal, Vol.18, No.1, 38-40, 1973.

[13] L.P. Menasce, J.H. Shanks, S.S. Banerjee, M. Harris. Follicular lymphoid hyperplasia of the hard palate and oral mucosa: report of three cases and a review of the literature, Histopathology, Vol.39, No.4, 353-358, 2001.

[14] D.L. Harsany, J. Ross, W.E. Fee Jr. Follicular lymphoid hyperplasia of the hard palate simulating lymphoma, Otolaryngology-Head and Neck Surgery, Vol.88, No.4, 349-356, 1980.

[15] J.M. Wright, A.R. Dunsworth. Follicular lymphoid hyper plasia of the hard palate: A benign lymph proliferative process, Oral Surgery, Oral Medicine and Oral Pathology Vol.55, No.2, 162-168, 1983.

[16] E. Peretz, M.H. Grunwald, E. Cagnano, S. Halevy. Follicular B-cell pseudolymphoma, Australian Journal of Dermatology, Vol.41, No.1, 48-49, 2000.

[17] E.R. Mopsik, J.C. Adrian, L.E. Klein. Follicular lymphoid Hyperplasia of the Hard Palate: Report of a case, Journal of Oral \& Maxillofacial Surgery, Vol.50, No.5, 538-540, 1992.

[18] R. Warnke, R. Levy. Immunopathology of follicular lymphomas A Model of B-Lymphocyte Homing, The New England Journal of Medicine, Vol.298, No.9, 481-486, 1978. 